\title{
Melanoma Screening Days During the Coronavirus Disease 2019 (COVID-19) Pandemic: Strategies to Adopt
}

\author{
Alessia Villani - Gabriella Fabbrocini - Claudia Costa • \\ Massimiliano Scalvenzi
}

Received: May 6, 2020 / Published online: May 28, 2020 (C) The Author(s) 2020

\begin{abstract}
Melanoma is one of the most common cancers, with an increasing incidence worldwide. Disease stage represents the most important prognosis factor; therefore, early diagnosis is essential for melanoma patients' survival rates. Following the outbreak in China, the coronavirus disease 2019 (COVID-19) pandemic has spread all over the world and the majority of dermatological visits have been postponed. These measures could cause a delay in melanoma diagnosis and management leading to an increase of morbidity, mortality and healthcare costs. Herein we propose an alternative model of skin cancer screening and the organization of screening campaigns in order to detect malignant lesions early during this emergency period.
\end{abstract}

Keywords: Dermatoscopy; Early detection; Melanoma; Prevention; Screening; Skin cancer

Digital Features To view digital features for this article go to https://doi.org/10.6084/m9.figshare.12349736.

\footnotetext{
A. Villani $(\bowtie) \cdot$ G. Fabbrocini $\cdot$ C. Costa .

M. Scalvenzi

Dermatology Unit, Department of Clinical Medicine

and Surgery, University of Naples Federico II,

Naples, Italy

e-mail: ali.vil@hotmail.it
}

\section{Key Summary Points}

Early diagnosis of melanoma is essential for melanoma patients' survival rates

During the coronavirus disease 2019 (COVID-19) pandemic the majority of dermatological visits have been postponed

Although teledermatology should be used to ensure patients' safety, there are some occasions, such as evaluation of pigmented lesions, in which face-to-face visits are required

Dermatologists and public health organizations should provide practical solutions to create a different model of skin cancer screening campaign in order to ensure cancer prevention and safe conditions for patients

\section{COMMENTARY}

Melanoma is one of the most common cancers, with a steadily and significantly increasing incidence worldwide. Among all the skin cancers it is the most serious, usually causing death if diagnosed too late and affecting all age 
groups, including adolescents [1]. Disease stage, corresponding to primary tumour thickness, represents the most important prognosis factor; therefore, early diagnosis is essential for melanoma patients' survival rates [2]. In the last decade several skin cancer screening campaigns have been strategically organized worldwide, in particular before the summer period, in order to increase awareness and promote whole-body self-examination among the entire population. These prevention campaigns resulted in higher detection of skin malignancies and increased patients' education about sun protection, skin cancer risk factors and detection of suspicious lesions [3].

Following the outbreak in China, the coronavirus disease 2019 (COVID-19) pandemic, called severe acute respiratory syndrome coronavirus (SARS-CoV-2), has spread all over the world requiring the adoption of severe preventive measures, including the order of home isolation.

Regarding dermatologic departments, the majority of outpatient procedures and dermatological treatments have been postponed, except for urgent visits and oncologic patients [4]. With the evolving of this crisis and no clear solutions, dermatologists have also adopted the use of teledermatology as a possible solution. Although teledermatology should be used to ensure patients' safety, there are some occasions, such as pigmented lesions evaluation, in which face-to-face visits are required [5]. A delay in melanoma diagnosis and management could lead to an increase of morbidity, mortality and healthcare costs. Another important issue to consider is skin cancer screening and the organization of screening campaigns in order to detect malignant lesions early. According to the preventive measures adopted, meetings or crowded places should be avoided until complete virus extinction, and melanoma screening campaigns, where usually a large part of the population takes part, will most likely be cancelled, causing a lot of failed or too late skin cancer diagnoses. Therefore, dermatologists and public health organizations should maintain efficiency during this crisis and provide practical solutions to create an alternative model of screening campaign in order to ensure cancer prevention with face-to-face visits with patients and safe conditions. An "alternative model" of prevention campaign should be based on the same principles of the original ones, but with the implementation of all information services including the use of telemedicine services.

An alternative model of screening campaign should include (1) patients' education regarding sun protection through a media campaign on TV, radio, newspapers and magazines; (2) leaflets with information about suncare, the most common skin cancers, how to recognize suspicious and risky lesions, and how to perform selfexamination, shared through the university websites, Facebook pages etc. and also in pharmacies; (3) the use of free phone applications, properly advertised, including instructions on the recognition of suspicious risky lesions, advertisements regarding sun protection or on the importance of periodic control visits; (4) the organization of a multiday screening event publicized in local newspapers and on Facebook pages, Twitter and university websites; in particular multiday screening could be organized on Saturday and Sunday for four consecutive weeks, to make possible to do this for no charge and have the clinicians and all staff available. Moreover, face-to-face visits will be booked through a unique "Melanoma Screening Campaign" e-mail created by the organizing department with a limited number each day. Free-of-charge consultations and whole-body dermatoscopic examination will be provided for each patient; visits will be held in the outpatient clinic every $30 \mathrm{~min}$, after patient triaging, and respecting all the preventive measures [5]. Primary prevention, mainly based on patients' education, and early detection and early treatment of skin malignancies have a key role in reducing morbidity, mortality and healthcare costs. Following the "alternative model" described above could be an interesting strategy to reach the highest possible number of people, also reaching adolescents via the use of web applications [6], and to maximize awareness of this public health problem, thus replacing in a different way the classic screening campaigns that will surely be cancelled during this emergency period, in order to avoid the risk of infection. 


\section{ACKNOWLEDGEMENTS}

Funding. No funding or sponsorship was received for this study or publication of this article.

Authorship. All named authors meet the International Committee of Medical Journal Editors (ICMJE) criteria for authorship for this article, take responsibility for the integrity of the work as a whole, and have given their approval for this version to be published.

Disclosures. Alessia Villani, Claudia Costa and Massimiliano Scalvenzi have nothing to disclose. Gabriella Fabbrocini is a member of the journal's Editorial Board.

Compliance with Ethics Guidelines. This article is based on previously conducted studies and does not contain any studies with human participants or animals performed by any of the authors.

Open Access. This article is licensed under a Creative Commons Attribution-NonCommercial 4.0 International License, which permits any non-commercial use, sharing, adaptation, distribution and reproduction in any medium or format, as long as you give appropriate credit to the original author(s) and the source, provide a link to the Creative Commons licence, and indicate if changes were made. The images or other third party material in this article are included in the article's Creative Commons licence, unless indicated otherwise in a credit line to the material. If material is not included in the article's Creative Commons licence and your intended use is not permitted by statutory regulation or exceeds the permitted use, you will need to obtain permission directly from the copyright holder. To view a copy of this licence, visit http:// creativecommons.org/licenses/by-nc/4.0/.

\section{REFERENCES}

1. Berwick M, Wiggins C. The current epidemiology of cutaneous malignant melanoma. Front BioSci. 2006;11:1244-54. https://doi.org/10.2741/1877.

2. Balch CM, Gershenwald JE, Soong SJ, et al. Final version of 2009 AJCC melanoma staging and classification. J Clin Oncol. 2009;27:6199-206.

3. Iannacone MR, Green AC. Towards skin cancer prevention and early detection: evolution of skin cancer awareness campaigns in Australia. Melanoma Manag. 2014;1(1):75-84. https://doi.org/10.2217/ mmt.14.6.

4. Wang Y, Wang Y, Chen Y, Qin Q. Unique epidemiological and clinical features of the emerging 2019 novel coronavirus pneumonia (COVID-19) implicate special control measures. J Med Virol. 2020. https:// doi.org/10.1002/jmv.25748.

5. Gomolin T, Cline A, Handler MZ. The danger of neglecting melanoma during the COVID-19 pandemic. J Dermatolog Treat. 2020;29:1-8. https://doi. org/10.1080/09546634.2020.1762844.

6. Villani A, Scalvenzi M, Fabbrocini G. Teledermatology: a useful tool to fight COVID-19. J Dermatolog Treat. 2020. https://doi.org/10.1080/09546634.2020. 1750557. 